\title{
Research on China's Regional Energy Efficiency Evaluation and Influencing Factors Based on the DEA-Tobit Model
}

\author{
Hong Jing Liang*, Jin Sheng Liu, Rong Wang, Ya Qin Song, Yuan Yuan Zhou \\ Nanjing Institute of Technology, Jiangning Science Park, Nanjing, China
}

Received: 24 November 2019

Accepted: 28 December 2019

\begin{abstract}
Our paper uses the ultra-efficient data envelopment analysis and Tobit model to evaluate the energy efficiency and regional differences of 30 provinces in China during 2006-2018. Based on this, the factors affecting energy efficiency in various regions of China are analyzed. The conclusions are as follows: From 2006 to 2018, China's energy efficiency has generally improved, indicating that energy efficiency is getting more and more attention, but the efficiency level is still relatively low. There is still much room for improvement, and there is a gap between regions. Increase the difference. From the regional perspective, the areas with high energy efficiency from high to low are the eastern, central and western regions. Analysis of the factors affecting energy efficiency shows that industrial structure, marketization level, economic development level, foreign direct investment, technological progress and energy prices all have an impact on energy efficiency, but for different regions the degree of impact is different, and the energy in the eastern region Efficiency is most affected by technological progress and marketization. The main factor affecting energy efficiency in the central region is the energy price level, while the factors affecting energy efficiency in the western region are mainly the level of industrial structure.
\end{abstract}

Keywords: DEA-Tobit model, energy efficiency, sustainable development, green development

\section{Introduction}

Energy is an indispensable production factor in people's production and life, and plays a vital role in the high-quality development of a regional economy. In 2018, China pointed out in the guidance on energy work that the energy consumption per unit of GDP fell

*e-mail: nanjinglhjs@163.com by more than $4 \%$ year-on-year. The realization of this goal depends on the improvement of energy efficiency. China has a large amount of energy resources, a vast territory and a large population, but its per capita possession is far below the world average, and its dependence on foreign countries is increasing year by year [1]. The BP World Statistical Yearbook 2017 indicates that China accounted for $23 \%$ of global energy consumption in 2016 and $27 \%$ of global energy consumption growth [2]. China's economic growth is in the process of accelerating industrialization 
and urbanization. As China's population continues to increase, energy resources will undoubtedly become an important pillar to ensure the sustainable and healthy development of China's social economy. The constant and long-term stable energy investment is not only related to national energy security and environmental issues, but also to the steady and sustainable development of the economy.

The contradiction between China's energy supply and demand has intensified, and the ecological environment has deteriorated frequently. The energy efficiency of different regions is greatly affected by factors such as resource endowment, economic level and structure. At this stage, China ranks $73^{\text {rd }}$ in the world in terms of energy efficiency - not only behind OECD countries such as Europe and the United States, but also behind developing countries such as India, Mexico and Brazil. Extensive energy use patterns have brought serious environmental pollution problems to China. At present, China's sulfur dioxide pollution, carbon dioxide pollution and fine particulate matter pollution rank first in the world. Among them, carbon dioxide emissions have accounted for $29 \%$ of the world's total carbon emissions, exceeding the combined carbon emissions of the United States and the European Union (2016 Global Carbon Budget Report) [3]. In 2016, 11 provinces and cities such as Beijing, Tianjin, Hebei, and Shanxi experienced large-scale persistent haze weather, which once reached 1.43 million $\mathrm{km}^{2}$, affecting more than 800 million people. Extensive energy use and the resulting environmental pollution problems have severely constrained the sustainable development of China's economy [4]. In order to alleviate the energy and environmental crisis, the Chinese government has done a lot of effective work on energy conservation and emission reduction, and formulated a series of energy sustainable development strategies to adapt to China's national conditions. China's " $13^{\text {th }}$ Five-Year Plan" proposes innovation, coordination and being green. For the concept of open, shared development, China will pay more attention to green development in the future, and strive to achieve sustainable development. Safeguarding energy security and improving energy efficiency are the core elements of the $13^{\text {th }}$ Five-Year Plan. In particular, the report of the $19^{\text {th }}$ National Congress put forward the "construction of a clean, low-carbon, safe and efficient energy system" to protect the health of the people and the sustainable development of the economy and society. It can be seen that saving energy, reducing energy consumption and reducing pollution emissions have become one of the important contents of improving the quality of economic development and transforming the mode of economic development [5]. However, there are obvious regional imbalances in China's economic development, and there are also obvious regional differences in energy efficiency. To improve China's overall energy efficiency, it is necessary to first improve the energy efficiency of each region according to regional differences. This has theoretical and practical significance for further promoting China's economic transformation and promoting sustainable development of the energy regional economy under the new economic normal.

In this realistic context, this paper combines China's current economic development under the new economic normal (based on the data of China's provinces), conducts in-depth research on the energy efficiency of each province, and measures the energy efficiency of each province to analyze the differences between the energy efficiency of each province. And the influencing factors have important practical significance for China to accelerate the implementation of the green development concept and achieve a clean, low-carbon and efficient sustainable development path, thereby improving the quality and efficiency of economic growth.

\section{Literature Review}

Energy is an indispensable input factor for economic growth, and it has an important impact on economic development. Research on the relationship between energy and economic development has always been one of the main concerns of economics. The research on energy efficiency in domestic and foreign literature mainly focuses on the following aspects:

The first is the measurement of energy efficiency; the measurement of energy efficiency mainly includes two methods: single factor energy efficiency measurement and total factor energy efficiency measurement, however, the calculation of singlefactor energy efficiency indicators is more limited, and the calculation of total factor energy efficiency indicators is more accepted by scholars. At present, the parametric method and the nonparametric method are two commonly used methods for measuring total factor energy efficiency. Rogg and Jaeger (2013) [5] applied a modified DEA model to evaluate the cost efficiency of municipal solid waste collection and processing in the Flanders region of Belgium. Blancard and Martin (2014) [6] used the ultra-efficient DEA algorithm to measure the agricultural energy efficiency of the algorithm country, and the result is not a fixed value. In addition, some literature uses the random frontier method (SFA) to measure energy efficiency. Lin and Long [7] used the SFA model to analyze energy efficiency and the energy saving potential of China's chemical industry. Based on the panel data of the chemical industry in 30 provinces of China from 2005 to 2011, the results show that Shanxi Province has the highest energy efficiency; Lin Boqiang and Du Kerui (2013) used the fixed-effect SFA model of panel data to measure China's interprovincial energy efficiency from 1997 to 2009, and discussed the impact of factor market distortion on energy efficiency [8]. Lin et al. (2015) also used the SFA model based on the surpassing logarithmic function hypothesis to analyze the energy efficiency and 
energy saving potential of China's chemical industry in 2005-2011 [9].

Second, based on the calculation of energy efficiency, many literatures began to compare and analyze the differences in energy efficiency between regions. Zhao Jinlou et al. (2013) [10] analyzed the coefficient of variation of energy efficiency in China from 1980 to 2010 and found that there are obvious differences in regional energy efficiency in China, and the overall trend is first rising and then decreasing; Shi Hongliang and Yang Xianming (2015) based on the DEA method, the total energy efficiency of the six cities in Yunnan Province from 2005 to 2013 was measured based on the DEA method, and the energy efficiency differences and energy saving potentials among the cities were investigated. Analysis [11] by Li Zhihe and Li Guoping (2010), used the DEA model and the panel data of 210 prefecture-level cities in China from 1995 to 2006 to measure the urban total factor energy efficiency, and analyzing the characteristics of urban total factor energy efficiency [12]. Keirstead (2013) used the data of 198 cities in the UK to measure urban energy efficiency through ratiometric indicators, regression residuals and DEA, and compared their advantages and disadvantages [13].

Third are the influence factors of energy efficiency. Birol and Keppler (2000) studied the impact of energy relative prices on energy efficiency and found that energy prices acted as a substitute for production factors [14]. Gao Zhenyu and Wang Yi (2006) studied the energy data of various provinces in China and showed that the level of economic development is also an important factor affecting energy efficiency [15]. Denison (1967) first studied the energy efficiency of different production sectors with different productivity, and believed that the allocation of energy factors between sectors with productivity differences would affect energy efficiency [16]. Samuels (1984) further studied that industrial structure optimization can improve energy efficiency [17]. Liu Hongmei and Tao Quan (2002) showed that RandD and talents can promote energy production capacity through product innovation and industrial innovation through the research on enterprise RandD and personnel training [18]. Paul Crompton and Yanrui Wu (2005) [19] and Fisher-Vanden et al. (2004) [20] analyzed the key factors affecting China's energy efficiency and considered that technology is the main driving force for improving energy efficiency. Qi Zhixin and Chen Wenying (2006) [21] passed the data of macro energy intensity in China from 1980 to 2003, and analyzed the reasons for the increase of energy efficiency in the industrial sector from 1993 to 2003 by using the Lagrangian factor decomposition method, and found that technological progress is the determinant of energy intensity impact.

\section{Methods}

\section{Super Efficient DEA}

Farrell first proposed in 1957 constructing a nonparametric convex surface to estimate the production front and calculate the relative efficiency, but it was not until 1978 that the famous operations researchers A. Charnes and W.W. Cooper proposed the first data envelopment analysis (DEA) model that has received wide attention and application. DEA is an efficiency evaluation method based on mathematical programming theory. Its purpose is to construct a non-parametric data envelope analysis frontier convex line segment through mathematical programming, so that efficient sample points are located on the leading edge and below the leading edge, and measure the efficiency value of the decision unit with the distance projected by the invalid point onto the leading edge. It is characterized in that the relative efficiency of the decision making unit (DMU) with the same input and output is compared and measured using the mathematical programming model without prior setting of a specific function form. For the multi-input and multi-output indicators, no prior input is required. Set the weight of the indicator and the relational expression between the indicators, which can eliminate the influence of many people's subjective factors, and the results obtained have strong objectivity. The DEA method can also be used to find the optimal situation of the decision-making unit. Effective decision-making units provide improved direction and a number of adjustments. It can be proved that the validity of DEA is equivalent to the Pareto efficient solution. These advantages of the DEA method make it widely used in the analysis of the effectiveness of technical efficiency, resource allocation efficiency, nonproductive enterprises and departments, and evaluate the efficiency of each decision-making unit [22-24].

Assuming that the production system has $n$ decision-making units, and that there are $\mathrm{S}$ species in each decision-making unit, and there are $\mathrm{m}$ inputs, the efficiency of the $\mathrm{i}$-th decision-making unit is $\theta$, and the DEA model is as follows:

$\operatorname{Min} \theta$

$$
\left\{\begin{array}{c}
-y_{i}+\sum_{i=1}^{n} Y_{i} \lambda_{i} \geq 0 \\
\theta x_{i}-\sum_{\substack{i=1 \\
\lambda \geq 0}}^{n} X_{i} \lambda_{i} \geq 0
\end{array}\right.
$$

...where $\theta$ scalar, $\lambda$ is a constant vector of $N \times 1$, the $\theta$ value obtained is the efficiency value of DMUi, generally $\theta \leq 1$, if $\theta=1$ means that the unit is technically valid and at the leading edge on. This is the efficiency model under the condition of constant returns to scale, known as the CCR model. 
However, the traditional DEA model cannot deal with energy efficiency problems involving undesired outputs. Most of them evaluate efficiency from both angle and radial. Angle refers to the evaluation of efficiency according to input-oriented or outputoriented, while radial refers to the efficiency of input and output according to a certain proportion. However, there is a phenomenon of redundant input or insufficient output in the production process. The traditional DEA model cannot consider the influence of "relaxation amount" on efficiency evaluation. If these slack problems are not taken into account, the resulting efficiency values will be inaccurate. The traditional DEA efficiency measurement method has been unable to meet the research needs.

This is because in the DEA efficiency measurement method, the efficiency of the optimal unit has the highest efficiency value of only 1 , and the efficiency of the optimal unit cannot be compared [25].

Anderson and Peterson (1993) [26] established an investment-oriented hyper-efficiency DEA model to compensate for this deficiency, and can make effective decision-making units with efficiency values greater than one. The super-efficient DEA (SE-DEA) model is as follows:

$$
\left\{\begin{array}{l}
\min \left[\theta-\varepsilon\left(\sum_{i=1}^{m} s_{i}^{-}+\sum_{r=1}^{s} s_{r}^{+}\right)\right] \\
\sum_{\substack{j=1 \\
j \neq k}}^{n} \lambda_{j} X_{i j}+s^{-} \leq \theta X_{0} \\
\sum_{\substack{j=1 \\
j \neq k}}^{n} \lambda_{j} Y_{j}-s^{+}=Y_{0} \\
\lambda_{j} \geq 0, \mathrm{j}=1,2, \ldots, \mathrm{n}, \quad s^{+} \geq 0 ; s^{-} \geq 0
\end{array}\right.
$$

...where $\lambda$ is the weight variable of DMU; $\theta$ is the parameter to be determined, slack variable $s_{r}^{+}, s_{r}$; $X$ is the input quantity; and $Y$ is the output quantity. The solution to the model is denoted by $\theta^{*}$. If $\theta^{*}<1$, it indicates that there is a virtual decision unit whose output is not lower than the output of the first $\mathrm{j}_{0}$ decision unit, and the input ratio is the input of the $\mathrm{j}_{0}$ decision units. This shows that $j_{0}$ is non-DEA valid.

If $\theta^{*}=1$ and the slack variables are all 0 , then the $j_{0}$ decision unit is DEA valid; and $\theta^{*}<1$ but the slack variable is not 0 , the $\mathrm{j}_{0}$ decision unit is valid for weak DEA.

\section{Tobit Model}

In this paper, the Tobit model is used to test the data. The Tobit model can overcome the deviation of the parameter values obtained by general linear regression. The model was founded by Tobin, and in 1958 Tobin first proposed the Tobit economic model. In the econometric literature, the Tobit model is a standard puncturing regression model in the restricted dependent variable model. The Tobit model is as follows:

$$
y_{i t}= \begin{cases}\alpha_{i t}+\beta^{T} x_{i t}+\varepsilon_{i t} & y_{i t} \geq 0 \\ 0 & y_{i t}<0\end{cases}
$$

...where the interpreted variable $\mathrm{y}_{\mathrm{it}}$ is the energy efficiency of the $t$-th year of the $\mathrm{i}$-th region. $\mathrm{X}_{\mathrm{it}}$ is the explanatory variable, $\beta^{\mathrm{T}}$ is the unknown parameter, and $\varepsilon_{\text {it }} \sim N(0, \sigma 2)$. This model is the intercepted regression model of the panel data, the explanatory variable $\mathrm{x}_{\text {it }}$ takes the actual observation value, and the interpreted variable $y_{i t}$ is in a restricted manner. When $y_{i t} \geq 0$ takes the actual observation; when $\mathrm{y}_{\mathrm{it}}<0$, the observation is truncated to $0 . \alpha_{i t}$ is the fixed effect of the t-year of region $\mathrm{i}$, which is an unknown constant.

\section{Results}

\section{China's Regional Energy Efficiency Calculation Results}

\section{Variable Selection}

This paper takes provincial energy efficiency as the research object and measures the regional energy efficiency of China's 30 provinces (including provinces, municipalities and autonomous regions) in 2006-2018. Because Tibet data is difficult to collect, it is excluded. The energy efficiency values considering undesired outputs are measured using an ultra-efficient SBM model containing undesired outputs, and the input and output factors are selected separately. Among them, the input factors include energy, manpower, and capital

Table 1. Indicator selection.

\begin{tabular}{|c|c|c|}
\hline Indicator & Secondary indicator & Third-level indicator \\
\hline \multirow{3}{*}{ Input } & Labor force & Number of employed people in the year (10,000 people) \\
\cline { 2 - 3 } & Capital & Capital stock (ten thousand yuan) \\
\cline { 2 - 3 } & Energy & Total energy consumption by provinces (10,000 tons of standard coal) \\
\hline \multirow{3}{*}{ Output } & Expected output & Per capita gdp (ten thousand yuan) \\
\cline { 2 - 3 } & Undesired output & Sulfur dioxide emissions (10,000 tons) \\
\cline { 2 - 3 } & & Carbon dioxide emissions (10,000 tons) \\
\hline
\end{tabular}


factors. The general selection variables are labor, capital stock, and energy consumption. The output factors include expected output and undesired output. The expected output variable selects the actual regional production of each province. Total value, undesired output variable selects sulfur dioxide emissions and carbon dioxide emissions. The specific indicators are selected in Table 1.

\section{Indicator Interpretation and Data Processing}

(1) Energy is expressed by the total energy consumption of each province. The data comes from the WIND database and is in tons of standard coal.

(2) Labor is expressed by the number of employed people in the current year. The number of employed people in that year $=$ (number of employed people at the beginning of the year + number of employed people at the end of the year) $/ 2$. The data comes from the 2006-2018 China Statistical Yearbooks.

(3) Capital is expressed in terms of capital stock. Since there is no data on the capital stock in the statistical yearbook, it needs to be calculated according to the given relevant data. The perpetual inventory method is generally used to estimate the capital stock, mainly referring to Zhang Jun et al. (2004). The index selection method for each variable in the capital stock calculation formula [27], $\mathrm{Ki}, \mathrm{t}$ is the capital stock of the region $\mathrm{i}$ in the $\mathrm{t}$-year, $\mathrm{Ii}, \mathrm{t}$ is the investment amount of the region $i$ in the t-year, measured by the total amount of fixed assets in the current year. The initial capital stock is the total fixed capital formation of each province in 2006 divided by $10 \%$. The specific calculation formula is as follows:

$$
K_{i, t}=K_{i, t-1}\left(1-\delta_{i, t}\right)+I_{i, t}
$$

...where $\mathrm{i}$ is the $\mathrm{i}$-th province and $\mathrm{t}$ is the $\mathrm{t}$-th period. The total fixed capital formation and the fixed asset investment price index are derived from the regional statistical yearbook from 2006 to 2018 .

(4) Expected output is expressed in terms of regional GDP. The data is derived from the WIND database and converts nominal GDP to actual regional GDP.

\section{(5) Unexpected output}

According to the air pollution that everyone is concerned about in current environmental pollution [28-30], this paper chooses two kinds of gas pollutants that may be generated by coal consumption: sulfur dioxide and carbon dioxide.

First, it is expressed by the amount of sulfur dioxide emissions. Data on sulfur dioxide emissions can be obtained directly from the statistical yearbook, and the data is from the 2006-2018 China Statistical Yearbooks.

Second, it is expressed in terms of carbon dioxide emissions. The $\mathrm{CO}_{2}$ emissions data cannot be directly obtained. Referring to other scholars' $\mathrm{CO}_{2}$ emission calculation method [21], multiplying the energy
Table 2. Various energy standard coal and carbon emission coefficients.

\begin{tabular}{|c|c|c|}
\hline Energy variety & $\begin{array}{c}\text { Standard coal } \\
\text { coefficient } \\
\text { (kg standard coal) }\end{array}$ & $\begin{array}{c}\text { Carbon emission } \\
\text { coefficient } \\
\text { (t carbon / tce) }\end{array}$ \\
\hline Coal $(\mathrm{kg})$ & 0.7143 & 0.7467 \\
\hline Diesel $(\mathrm{kg})$ & 1.4571 & 0.5913 \\
\hline Gasoline $(\mathrm{kg})$ & 1.4714 & 0.5532 \\
\hline Kerosene $(\mathrm{kg})$ & 1.4714 & 0.3416 \\
\hline Crude oil $(\mathrm{kg})$ & 1.4286 & 0.5854 \\
\hline Fuel oil $(\mathrm{kg})$ & 1.4286 & 0.6176 \\
\hline Coke $(\mathrm{kg})$ & 0.9714 & 0.1128 \\
\hline Electricity $(\mathrm{kw} . \mathrm{h})$ & 0.1229 & 2.2132 \\
\hline Natural gas $\left(\mathrm{m}^{3}\right)$ & 1.3300 & 0.4479 \\
\hline
\end{tabular}

Source: China Energy Statistical Yearbook 2018 and IPCC

Guidelines for National Greenhouse Gas Inventories (2006)

consumption by the corresponding carbon emission coefficient, this paper adopts the commonly used $\mathrm{CO}_{2}$ emission accounting method, and the calculation formula is: $\mathrm{C}=\sum \mathrm{E} \mathrm{j} \times \mathrm{Kj}$, where $\mathrm{C}$ is the $\mathrm{CO}_{2}$ emission of an energy source, $\mathrm{Ej}$ is the main energy consumption, and $\mathrm{Kj}$ is the carbon emission coefficient of the energy. The more commonly used $\mathrm{K} \mathrm{j}$ carbon emission coefficient is the UNCC published IPCC data, as shown in Table 2.

\section{China's Regional Energy Efficiency Calculation Results}

Using DEAP2.1 software, the determined input and output indicators are substituted into the model and the results are shown in Table 3.

The efficiency value of the eastern region has been the highest efficiency region in China's three major regions during 2006-2018. The average efficiency value is 0.738 , and the average efficiency value of the whole region is maintained above 0.68 . The efficiency value of the central region is three. In the middle of the large area, but still below the national average, there is a big gap with the eastern region. During the period of 2006-2018, the overall trend showed a slow growth trend, which gradually stabilized above 0.5 from the initial 0.391. The overall trend is the same as the national average energy efficiency value. The efficiency value of the western region is in the final position in the three regions, far lower than the eastern region, and its efficiency value has been around 0.4. It is worth noting that the average energy efficiency of the central and western regions are very close, which is numerous. There are some discrepancies in the research results of the literature. On the one hand, it may be because the years of research selection are different, but the main reason is that most of the studies do not analyze 
Table 3. Measurement results.

\begin{tabular}{|c|c|c|c|c|c|c|c|c|c|c|c|c|c|c|c|}
\hline & Region & 2006 & 2007 & 2008 & 2009 & 2010 & 2011 & 2012 & 2013 & 2014 & 2015 & 2016 & 2017 & 2018 & Mean \\
\hline \multirow{11}{*}{ Eastern } & Beijing & 0.935 & 0.937 & 0.955 & 0.921 & 0.944 & 0.958 & 0.984 & 0.999 & 1.032 & 1.066 & 1.176 & 1.229 & 1.453 & 1.045 \\
\hline & Tianjin & 0.587 & 0.599 & 0,601 & 0.692 & 0.603 & 0.612 & 0.623 & 0.644 & 0.673 & 0.693 & 0.701 & 0.712 & 0.745 & 0.657 \\
\hline & Hebei & 0.365 & 0.373 & 0.379 & 0.364 & 0.387 & 0.399 & 0.409 & 0.431 & 0.451 & 0.471 & 0.482 & 0.492 & 0.501 & 0.423 \\
\hline & Liaoning & 0.377 & 0.381 & 0.385 & 0.377 & 0.388 & 0.398 & 0.409 & 0.419 & 0.438 & 0.449 & 0.456 & 0.476 & 0.499 & 0.419 \\
\hline & Shanghai & 0.903 & 0.913 & 0.933 & 0.921 & 0.935 & 0.944 & 0.955 & 0.967 & 0.977 & 0.984 & 0.988 & 1.023 & 1.067 & 0.962 \\
\hline & Jiangsu & 0.688 & 0.689 & 0.698 & 0.691 & 0.501 & 0.533 & 0.546 & 0.576 & 0.588 & 0.599 & 0.623 & 0.644 & 0.688 & 0.620 \\
\hline & Zhejiang & 0.723 & 0.734 & 0.745 & 0.733 & 0.746 & 0.766 & 0.776 & 0.789 & 0.797 & 0.804 & 0.834 & 0.855 & 0.876 & 0.783 \\
\hline & Fujian & 0.811 & 0.823 & 0.835 & 0.811 & 0.822 & 0.837 & 0.844 & 0.855 & 0.876 & 0.894 & 0.911 & 0.933 & 0.945 & 0.861 \\
\hline & Shandong & 0.711 & 0.713 & 0.745 & 0.732 & 0.739 & 0.751 & 0.769 & 0.783 & 0.799 & 0.809 & 0.822 & 0.833 & 0.845 & 0.773 \\
\hline & Guangdong & 0.734 & 0.736 & 0.745 & 0.733 & 0.749 & 0.765 & 0.774 & 0.789 & 0.799 & 0.823 & 0.843 & 0.866 & 0.894 & 0.788 \\
\hline & Hainan & 0.723 & 0.733 & 0.745 & 0.755 & 0.734 & 0.749 & 0.764 & 0.788 & 0.794 & 0.827 & 0.843 & 0.863 & 0.883 & 0.785 \\
\hline \multicolumn{2}{|c|}{ Eastern mean } & 0.687 & 0.694 & 0.717 & 0.703 & 0.686 & 0.701 & 0.714 & 0.730 & 0.748 & 0.765 & 0.789 & 0.811 & 0.854 & 0.738 \\
\hline \multirow{8}{*}{ Central } & Shanxi & 0.301 & 0.311 & 0.319 & 0.311 & 0.324 & 0.335 & 0.345 & 0.358 & 0.376 & 0.384 & 0.398 & 0.401 & 0.423 & 0.353 \\
\hline & Jilin & 0.311 & 0.318 & 0.323 & 0.329 & 0.344 & 0.356 & 0.367 & 0.373 & 0.377 & 0.388 & 0.397 & 0.402 & 0.423 & 0.362 \\
\hline & Heilongjiang & 0.511 & 0.514 & 0.526 & 0.518 & 0.527 & 0.546 & 0.553 & 0.568 & 0.578 & 0.598 & 0.604 & 0.628 & 0.638 & 0.562 \\
\hline & Anhui & 0.333 & 0.349 & 0.364 & 0.351 & 0.359 & 0.376 & 0.382 & 0.394 & 0.402 & 0.428 & 0.433 & 0.439 & 0.449 & 0.389 \\
\hline & Jiangxi & 0.332 & 0.339 & 0.345 & 0.331 & 0.352 & 0.354 & 0.367 & 0.387 & 0.399 & 0.413 & 0.434 & 0.449 & 0.472 & 0.383 \\
\hline & Henan & 0.323 & 0.328 & 0.333 & 0.339 & 0.349 & 0.362 & 0.384 & 0.394 & 0.428 & 0.439 & 0.449 & 0.482 & 0.489 & 0.392 \\
\hline & Hubei & 0.522 & 0.532 & 0.539 & 0.529 & 0.541 & 0.555 & 0.568 & 0.578 & 0.593 & 0.605 & 0.623 & 0.633 & 0.652 & 0.575 \\
\hline & Hunan & 0.492 & 0.491 & 0.499 & 0.483 & 0.501 & 0.529 & 0.538 & 0.552 & 0.562 & 0.582 & 0.599 & 0.629 & 0.634 & 0.545 \\
\hline \multicolumn{2}{|c|}{ Central mean } & 0.391 & 0.398 & 0.406 & 0.399 & 0.412 & 0.427 & 0.438 & 0.451 & 0.464 & 0.480 & 0.492 & 0.508 & 0.523 & 0.445 \\
\hline \multirow{11}{*}{ Western } & Neimenggu & 0.273 & 0.284 & 0.293 & 0.272 & 0.288 & 0.31 & 0.334 & 0.349 & 0.364 & 0.374 & 0.388 & 0.404 & 0.433 & 0.336 \\
\hline & Guangxi & 0.342 & 0.347 & 0.331 & 0.316 & 0.333 & 0.353 & 0.366 & 0.381 & 0.398 & 0.424 & 0.429 & 0.443 & 0.465 & 0.379 \\
\hline & Chongqing & 0.543 & 0.549 & 0.553 & 0.562 & 0.549 & 0.547 & 0.539 & 0.537 & 0.541 & 0.533 & 0.529 & 0.528 & 0.511 & 0.540 \\
\hline & Sichuan & 0.287 & 0.276 & 0.289 & 0.276 & 0.299 & 0.319 & 0.337 & 0.345 & 0.365 & 0.374 & 0.388 & 0.392 & 0.401 & 0.334 \\
\hline & Guizhou & 0.224 & 0.221 & 0.225 & 0.219 & 0.227 & 0.239 & 0.248 & 0.236 & 0.256 & 0.276 & 0.287 & 0.298 & 0.343 & 0.254 \\
\hline & Yunnan & 0.343 & 0.349 & 0.476 & 0.343 & 0.357 & 0.463 & 0.366 & 0.388 & 0.401 & 0.423 & 0.426 & 0.444 & 0.446 & 0.398 \\
\hline & Shaanxi & 0.342 & 0.334 & 0.347 & 0.341 & 0.358 & 0.368 & 0.381 & 0.396 & 0.402 & 0.435 & 0.439 & 0.452 & 0.471 & 0.390 \\
\hline & Gansu & 0.234 & 0.239 & 0.249 & 0.241 & 0.252 & 0.264 & 0.288 & 0.298 & 0.313 & 0.33 & 0.354 & 0.374 & 0.399 & 0.295 \\
\hline & Qinghai & 0.493 & 0.523 & 0.534 & 0.522 & 0.543 & 0.555 & 0.576 & 0.588 & 0.581 & 0.619 & 0.634 & 0.649 & 0.676 & 0.576 \\
\hline & Ningxia & 0.522 & 0.534 & 0.535 & 0.531 & 0.549 & 0.552 & 0.563 & 0.583 & 0.598 & 0.611 & 0.624 & 0.645 & 0.665 & 0.578 \\
\hline & Xinjiang & 0.342 & 0.349 & 0.359 & 0.352 & 0.369 & 0.382 & 0.399 & 0.402 & 0.429 & 0.438 & 0.446 & 0.466 & 0.481 & 0.395 \\
\hline \multicolumn{2}{|c|}{ Western mean } & 0.359 & 0.364 & 0.381 & 0.361 & 0.375 & 0.396 & 0.401 & 0.410 & 0.439 & 0.440 & 0.451 & 0.464 & 0.483 & 0.408 \\
\hline \multicolumn{2}{|c|}{ National mean } & 0.488 & 0.494 & 0.504 & 0.497 & 0.499 & 0.516 & 0.525 & 0.539 & 0.563 & 0.570 & 0.586 & 0.603 & 0.630 & 0.539 \\
\hline
\end{tabular}

the environmental factors as the output of energy utilization, resulting in deviations in the measurement results of energy efficiency.

From a single province, there are significant differences in energy efficiency. Provinces such as Beijing, Fujian, Guangdong, Shanghai, Hainan, Qinghai, and Ningxia have higher energy efficiency, and energy use and pollution emissions are at relatively optimal levels. Among them, Beijing, Shanghai, Guangdong and other provinces are located in economically developed areas along the eastern coast. They have strong technical strength and have laid a solid foundation for their rapid economic growth. They also provide a good technical support environment for energy conservation and emission reduction. Hainan, Qinghai, Ningxia and other provinces also showed high energy efficiency during the inspection period. The technical conditions of these provinces are obviously inferior to the developed coastal provinces in the east, but the industrial structure is beneficial to energy conservation and emission reduction to a certain extent. The pillar industry is dominated by primary and tertiary industries, rather than secondary industries with high energy consumption and high pollution. For example, Hainan's real estate industry, Qinghai and Ningxia's tourism and agriculture and animal husbandry are all pillar 
industries. Therefore, structural factors may be the main reason for the high energy efficiency of these provinces; while Hebei, Shanxi, Jilin, Jiangxi, Henan, Guangxi, Sichuan and other provinces are not DEA effective, energy efficiency has been at a low level during the inspection period. Most of the industrial structures in these provinces are mainly energy-intensive secondary industries, and there is still a certain gap between the technical level and the developed coastal provinces in the eastern coastal areas. As a result, there are resource crowding in the economic growth process of these provinces, and energy waste is serious. The pressure on environmental protection is also increasing, and it is a key area of concern for China's energy conservation and emission reduction policies.

\section{Tobit Model Regression Analysis}

\section{Variable Selection}

In view of China's energy efficiency, it is necessary to conduct an analysis of energy efficiency itself and to conduct in-depth exploration of its influencing factors. Therefore, this paper will use the Tobit model to analyze the influencing factors of China's regional energy efficiency. The impact variables are selected as follows:

(1) Marketization level (MD).

When the level of marketization is higher, the level of allocation of energy elements will be higher, and energy efficiency also will be higher, and the technological innovation of energy will be faster. The degree of marketization reflects the government's degree of intervention and control of the market. This article uses the proportion of non-state-owned enterprises in the labor force to measure the level of marketization. The data comes from the China Statistical Yearbook.

(2) Energy price level (EP).

As an important cost of economic production activities, energy prices will inevitably affect people's production and life decisions. There are many types of energy, including various coal products, petroleum products, natural gas products, and production and domestic electricity. It is difficult to combine the prices of all energy sources with one price. Considering the changes in various energy prices will inevitably affect people. The energy use situation, so you can consider the use of per capita energy consumption from the side to comprehensively reflect the price level of energy.

(3) Economic development level (ED).

On the one hand, with the continuous advancement of industrialization, the total energy consumption of the whole society will inevitably rise gradually. At the same time, the energy intensity will increase from the empirical data. On the other hand, the total energy consumption in some economically developed regions is high due to the tertiary industry accounts for a high proportion of GDP, but the energy intensity does not increase proportionally. Therefore, the level of economic development can be regarded as an important factor. This paper selects per capita GDP as an indicator to measure the level of economic development.

(4) Industrial structure (ES).

We know that the demand for energy in agriculture (primary industry), industry (second industry) and service industry (third industry) is different. Under normal circumstances, the demand for energy in the secondary industry is large, and the tertiary industry has energy. The demand is the lowest, and the primary industry is in the middle. This paper selects the proportion of the tertiary industry as a whole of GDP as an indicator to measure the industrial structure.

(5) Technological advancement (TE).

The comprehensive impact of technological progress on energy is not only reflected in the application of technology, but also in the whole process of energy input as an economic factor into economic output. There are two main aspects to technological progress: one is technological innovation, that is, narrow technological progress; the other is management, institutional optimization, such as improvement of transportation technology, introduction of advanced equipment, or optimization of existing management systems. It can improve energy efficiency and reduce energy consumption during production. Based on the actual situation in China and the availability of data, this paper selects the number of patents obtained by enterprises as an indicator to measure the level of technological progress.

(6) Foreign direct investment (FDI).

The impact of foreign direct investment on energy efficiency is that the rapid growth of investment scale will lead to an excessive increase in total energy consumption. Foreign investment in high energyconsuming industries will lead to a sharp increase in total energy consumption and a decline in energy efficiency. On the contrary, high-tech industries such as the information industry and electronic information industry invested by foreign investors are industries with low energy consumption and high energy efficiency. Investing in these industries will improve energy efficiency. Therefore, the scale of foreign direct investment is chosen as a measure of the impact of investment on energy efficiency.

The above variables are based on panel data of 30 provinces, municipalities and autonomous regions (except Tibet) in China from 2006 to 2018. The data sources of each indicator are as follows: The GDP data calculated at constant price is expressed by the regional GDP calculated from the constant price in 2006. The GDP of each year is converted according to the corresponding GDP conversion index, and the GDP conversion index data from the National Bureau of Statistics database. Energy consumption data comes from the Energy Statistics Yearbook. Hong Kong, Macao and Taiwan and foreign investment data are sourced from the National Research Network database. The internal expenditure data of RandD funds is 
Table 4. Regression results.

\begin{tabular}{|c|c|c|c|}
\hline \multirow{2}{*}{$\alpha$} & Eastern & Central & Western \\
\hline \multirow{2}{*}{ MD } & NA & $1.01^{*}$ & $1.011^{*}$ \\
\cline { 3 - 4 } & $0.561 * * *$ & $0.832 * * *$ & $0.242^{*}$ \\
\cline { 2 - 4 } & $(0.0001)$ & $(0.0000)$ & $(0.0501)$ \\
\hline \multirow{2}{*}{ EP } & $0.153^{* * *}$ & 0.212 & -0.051 \\
\cline { 2 - 4 } & $(0.0000)$ & $(0.1711)$ & $(0.3566)$ \\
\hline \multirow{2}{*}{ ED } & $0.125^{* * *}$ & $-0.101 * * *$ & $-0.068 * * *$ \\
\cline { 2 - 4 } & $(0.0000)$ & $(0.0001)$ & $(0.000)$ \\
\hline \multirow{2}{*}{ ES } & $0.232 * * *$ & 0.084 & $0.479 * * *$ \\
\cline { 2 - 4 } & $(0.0000)$ & $(0.2654)$ & $(0.0012)$ \\
\hline \multirow{2}{*}{ TE } & $0.414 * * *$ & $0.015 * * * *$ & $0.345 * * * *$ \\
\cline { 2 - 4 } & $(0.0020)$ & $(0.0011)$ & $(0.0014)$ \\
\hline \multirow{2}{*}{ FDI } & $0.122 * * *$ & -0.031 & -0.048 \\
\cline { 2 - 4 } & $(0.0000)$ & $(0.3321)$ & $(0.3811)$ \\
\hline
\end{tabular}

Note: $* * *, * * *$ are significant under $1 \%, 5 \%$, and $10 \%$ conditions respectively. The data in parentheses is $\mathrm{P}$ value, and NA means no data.

derived from the China Science and Technology Statistical Yearbook. Other data are derived from the China Statistical Yearbook and the statistical yearbooks of the provinces.

\section{Tobit Regression Results and Analysis}

In this paper, based on the existing literature, considering the availability of data, the marketization level, energy price level, economic development level, industrial structure, technological progress and foreign direct investment as explanatory variables and regional energy efficiency (recorded as EE). For the explanatory variables, the sampling interval is 2006-2018, and the following regression equation is established.

The regression results of the Tobit model in various regions of China are shown in Table 4 . In this paper, the estimated results obtained by using the software Stata14.0 are shown in Table 4.

(1) The impact of marketization on energy efficiency.

The impact of marketization on energy efficiency is positive and the impact is significant. The degree of marketization defined in this paper reflects the degree of government intervention and control of the market. The regression results on the degree of marketization show that the greater the proportion of non-state-owned enterprises in the labor force, the higher the energy efficiency. The degree of marketization has changed from three regions to the central, eastern and western regions. The central region has become the most significant region affected by the degree of marketization. The coefficient is estimated to be 0.832 , which means that the number of non-state-owned enterprises is in the labor force. The proportion increased by $1 \%$, and the energy efficiency in the central region increased by $0.832 \%$. The degree of marketization can lead to an increase in energy efficiency, which may be due to the nonlabor population mainly working in private enterprises and foreign-funded enterprises. These enterprises are based on the principle of maximizing cost-saving benefits, and the regulation of energy utilization will be stricter. Improve energy efficiency. This performance is particularly evident in the central region. In the eastern region, enterprises are highly privatized, and their resource allocation mainly plays a role through market regulation. As the government's intervention in production decreases, the effectiveness of market allocation resources is enhanced, thus affecting energy efficiency.

(2) The impact of energy prices on energy efficiency.

It can be seen that the impact of energy prices on energy efficiency varies from region to region. Energy prices have no significant positive impact on the central region. Energy prices have no significant negative impact on energy efficiency in the western region, suggesting that energy efficiency has declined as energy prices have risen, but this effect is not obvious. This shows that the market regulation mechanism of energy prices in the central and western regions is not perfect enough to optimize the allocation of resources through changes in energy prices. The energy price in the eastern region has a significant positive impact on energy efficiency, with an impact coefficient of 0.153 , which indicates that for every $1 \%$ increase in the energy price index, the energy efficiency in the eastern region increases by $0.153 \%$. This shows that the market mechanism of the energy market in the eastern region has been initially improved. The energy allocation can be optimized through the price adjustment mechanism of the energy market, but its coefficient is small, indicating that this mechanism still has the potential to continue to improve.

(3) The level of regional economic development.

In the eastern region, the coefficient of elasticity of the impact of per capita GDP on energy efficiency is positive, and the effect on the central and western regions is negative. The economic growth mode in the east is obviously better than that in the middle and west. The eastern region pays more attention to the adjustment of industrial structure, the quality of economic growth, and the development of sustainable economy. These development directions are conducive to the improvement of energy efficiency in the east. However, although the economic growth mode of the central and western regions has been greatly improved compared with the previous ones, the excessive use of resources and the introduction of heavy polluting industries still exist, which will cause a decline in energy efficiency, indicating that the economic 
development has caused a large environmental impact. The impact, while at the current economic level, does not reduce energy efficiency, so it presents a negative correlation.

(4) The impact of industrial structure on energy efficiency.

The industrial structure has positive impacts on energy efficiency in the eastern, central and western regions. The impact coefficients are 0.232 , 0.084 , and 0.479 , respectively. It can be seen that the impact of industrial structure on the western region is more obvious, and the proportion of the tertiary industry is increased. It can significantly improve energy efficiency in the western region. However, the estimated coefficient in the central region did not pass the significance test, indicating that the improvement of industrial structure has no significant effect on the improvement of energy efficiency in the central region. This is because the central region has historically been a gathering area for heavy industry. The accelerated development of industry makes it difficult to reduce the energy consumption of these high-energy-consuming industries, while the impact of the tertiary industry on energy efficiency is less important [31].

(5) The impact of technological progress on energy efficiency.

Technological progress has a significant positive impact on energy efficiency in the eastern, central and western regions, with the eastern region having the largest impact coefficient of 0.414. This shows that the energy efficiency of the eastern region can be significantly improved by drawing on advanced foreign production technologies. The influence coefficient of the western region is in the middle, indicating the support of the policy of large-scale development in western China; the western region has also improved energy efficiency to some extent by introducing foreign advanced energysaving and production technologies. The central region is less affected by technological progress, which may be due to an insufficient selection of indicators. Technological progress in the central region may lead to technological advancement through domestic technology introduction. Therefore, the impact of foreign service and cargo introduction on technological improvement is not obvious [32]. Technological progress in the central region has not had a strong impact on improving energy efficiency. It may also be that the introduction of energy-saving technologies in the central region has not received sufficient attention, leading to technological progress that has not fully played a role in improving energy efficiency. In addition, it should be noted that the technical progress indicators discussed in this paper are technological advances triggered by the introduction of foreign countries. Here, due to the difficulty in obtaining data, the technological progress through domestic independent innovation is neglected.

(6) The impact of foreign direct investment on energy efficiency has different characteristics in different regions..
Foreign direct investment is significantly positive for the energy efficiency of the eastern region, but the central and western regions have not passed the significance level test of $10 \%$, and the sign is negative. On the one hand, this may be because foreign direct investment is mainly concentrated in the eastern coastal region. The technology brought by foreign investment is the increase of the level makes the production frontier move outward. For the central and western regions, the distance from the production frontier is further widened, but the energy efficiency level of the entire region has decreased. On the other hand, it may be that the FDI has promoted regional economic growth in the central and western regions and increased investment levels, while the central and western regions of China are dominated by resource industries, which may lead to increased resource development and negative environmental effects [33].

\section{Conclusions}

This paper used super-efficient data envelopment analysis and Tobit model analysis to study the superefficient energy efficiency values, energy efficiency changes, and energy efficiency factors in China's 30 provinces from 2006 to 2018. The conclusions are as follows:

From 2006 to 2018, China's regional energy efficiency value has generally improved, but the overall efficiency level is still relatively low, and there is still much room for improvement. According to the evaluation of energy efficiency, it can be seen that the regions from high to low energy efficiency are in turn the eastern, central, and western regions. The energy efficiency of the eastern region has shown a significant upward trend, but the growth rate has declined in recent years. The overall technical level of the eastern region is higher than that of the central and western regions. It is at a higher level in terms of improving energy efficiency, so the improvement space is smaller than that of the central and western regions. In the western region, there has been a decrease in the increase; the energy efficiency in the central region has been relatively stable, showing a slight upward trend. The energy efficiency in the western region has always been lower than the national average, but it has been slowly increasing. The energy efficiency of Shanghai and Beijing in 30 provinces and cities in the country has exceeded 1.0 in recent years, and it is the region with the highest energy efficiency. The average energy efficiency of Jiangsu, Zhejiang, Hainan, and Guangdong also exceeded 0.8 in many years, which is relatively low. Beijing's energy efficiency has increased rapidly, especially since 2014, and its energy efficiency has always been the highest in the country. Shanxi, Inner Mongolia, Jilin and other provinces with rich energy reserves have relatively low energy efficiency, and the improvement trend is not obvious. The energy efficiency 
of the western region is at the lowest level of the three regions. The energy efficiency of eight provinces in the western region is less than 0.4 . It can be seen that there is still much room for improvement in the energy efficiency of the western region.

This article analyzes the influencing factors of energy efficiency, and the results show that industrial structure, degree of marketization, level of economic development, foreign direct investment, technological progress, and energy prices all have an impact on energy efficiency, but the degree of impact is different in various regions. Among them, technological progress and the degree of marketization have the most obvious impact on energy efficiency in the eastern region, indicating that energy efficiency in the eastern region can be effectively improved by increasing the degree of marketization and promoting technological progress; the factor that has the greatest impact on energy efficiency in the central region is the energy price level. This is inseparable from the industrial structure in the central region that is dominated by heavy industry. The optimization of the industrial structure and the strengthening of price controls can effectively improve the energy efficiency of the central region; the factor that has the greatest impact on the western region is the level of the industrial structure, which is higher than that of the eastern region. And Central China, explaining that through adjustment of the economic structure, the proportion of the tertiary industry can be increased to achieve the goal of improving energy efficiency.

\section{Acknowledgements}

This research was supported by the Nanjing Institute Of Technology Youth Science Fund Project, "Research on the mechanism and incentive mechanism of colleges and universities innovation teams in Jiangsu Province" (funding project No. qkj201706); the Nanjing Institute of Technology Higher Education Research Project, "Research on the mechanism of colleges and universities innovation team's efficiency increase based on the "field theory"" (funding project No. 2018yb08).

\section{Conflict of Interest}

The authors declare no conflict of interest.

\section{References}

1. WU J.,TAN T., YANG H. Research on China's Total Factor Energy Efficiency Evaluation - Based on Inseparable Three-Phase DEA Model. Mathematical Statistics and Management, 3, 418, 2019.

2. YUE L., YANG Y.H. Research on Time and Space Differentiation of Green Total Energy Efficiency in Countries along the Belt and Road Initiative - Based on
Super Efficiency DEA Model and GML Index Method. Economic Problems Exploration, 6, 111, 2019.

3. ZENG S.L., ZHANG Y.X., DENG X. Progress and Prospects of Research on Industrial Total Factor Energy Efficiency. Ecological Economy, 11, 25, 2018.

4. WANG L.Z., DING Y. The Dilemma of Beijing-TianjinHebei Haze Cooperation and Its Solution. Journal of the Party School of the CPC Central Committee, 3, 74, 2016.

5. WANG X.H., FENG Y.C. Impact of smog pollution on the quality of urban development in China. China Population • Resources and Environment, 29 (8), 1, 2019.

6. ROGGE N., JAEGER S.D. Measuring and explaining the cost efficiency of municipal solid waste collection and processing services. Omega, 41 (4), 653, 2013.

7. BLANCARD S., MARTIN E. Energy efficiency measurement in agriculture with imprecise energy content information. Energy Policy, 66, 198, 2014.

8. LIN B., LONG H. A stochastic frontier analysis of energy efficiency of China's chemical industry. Journal of Cleaner Production, 87 (1), 235, 2015.

9. LIN B.Q., DU K.R. The impact of factor market distortion on energy efficiency. Economic Research, 9, 125, 2013.

10. LIN B.Q., LONG H.Y. A Stochastic Frontier Analysis of Energy Efficiency of China's Chemical Industry. Journal of CleanerProduction, 87, 235, 2015.

11. ZHAO J.L., LI G., SU S. Regional Differences and Convergence Analysis of China's Energy Efficiency - An Empirical Study Based on Stochastic Frontier Analysis and Panel Unit Roots. Chinese Management Science, 4, 175, 2013.

12. SHI H.L., YANG X.M. The study of the total factor energy efficiency of the six major urban agglomerations in Yunnan based on the analysis of the panel data from the perspective of environmental regulation. Journal of Kunming University of Science and Technology: Social Science Edition, 12, 66, 2015.

13. LI Z., LI G.P. Analysis of the characteristics and influencing factors of urban energy efficiency in China. Economic Theory and Economic Management, 7, 17, 2010

14. KEIRSTEAD J. Benchmarking Urban Energy Efficiency in the UK. Energy Policy, 63, 575, 2013.

15. BIROL F., KEPPLER J.H. Price, technology development and the rebound effect. Energy Policy, 28, 86, 2000.

16. GAO Z.Y., WANG Y. Regional Division of China's Energy Productivity and Analysis of Influencing Factors. Quantitative Economics of Economics and Technology, 23 (9), 46, 2006

17. DENISON E.F. Why growth rates differ: Postwar experience in nine western countries. Washington: Brookings Institution Publishing, 1967.

18. SAMUELASETA L. Ptential Production of Energy cane for fuel in the caribbean. Energy progress, 4, 249, 1984.

19. LIU H.M., TAO Q. Analysis of the Motivation of Energy Density Decline in Large and Medium-sized Industrial Enterprises. Statistic Research, 19 (9), 30, 2002.

20. CROMOPTON P., WU Y.R. Energy consumption in China: past trends and future directions. Energy Economics, 27, 195, 2005.

21. FISHER-VANDEN K., JEFFERSON G.H. JINGKUI M., JIANYI X. Technology development and energy Productivity in China. Energy Economics, 28, 690, 2006.

22. QI Z.X., CHEN W.Y. Structural Adjustment or Technological Progress? - Analysis of Factors Affecting China's Energy Efficiency Improvement after Reform and Opening up. Shanghai Economic Research, 3, 08, 2006. 
23. LIAN T., MA T., JIE C., YOU W. The effects of environmental regulation on the industrial location of China's manufacturing. Natural Hazards, 80 (2), 1381, 2016.

24. HE A.P., AN M.T. Local government competition, environmental regulation and green development efficiency. China population, resources and environment, 3, 21, 2019.

25. MIYATA M. Energy efficiency evaluation of multiple splitsystem air conditioners with unbalanced load operation for building energy simulation. IOP Conference Series Earth and Environmental Science, 238, 1, 2019.

26. SHI C., GAO W., TIAN L. Research on a Multi-scenario Energy Efficiency Evaluation Method for an Industrial Park Multi-energy System,Advances in Green Energy Systems and Smart Grid. Springer, Singapore, 2018.

27. ANDERSEN P., PETERSEN N.C.A Procedure for Ranking Efficient Units in Data Envelopment Analysis. INFORMS, 1993.

28. ZGANG J., WU G.Y., ZHANG J. P.Estimation of China's Inter-provincial Material Capital Stock: 1952-2000. Economic Research, 10, 35, 2004.

29. ALMALKAWI A.T., SOROUSHIAN P., SHRESTHA S.S. Evaluation of the Energy-Efficiency of an Aerated SlurryInfiltrated Mesh Building System with Biomass-Based Insulation. Renewable energy, 133, 797, 2019.
30. BROGIOLI D., LAMANTIA F., YIP N.Y. Energy efficiency analysis of distillation for thermal regenerative salinity gradient power technologies. Renewable energy, 133, 1034, 2019.

31. XIONG S., MA X., JI J. The impact of industrial structure efficiency on statistical industrial energy efficiency in China. Journal of cleaner production, 215, 952, 2019.

32. YANG Z., WEI X. The measurement and influences of China's urban total factor energy efficiency under environmental pollution: Based on the game crossefficiency DEA. Journal of cleaner production, 209, 439, 2019.

33. LIU S., GAO H., HE C. Experimental evaluation of highly efficient primary and secondary amines with lower energy by a novel method for post-combustion $\mathrm{CO}_{2}$ capture. Applied energy, 233, 443, 2019.

34. ASHOURI M., HAGHIGHAT F., FUNG B.C.M. Development of a ranking procedure for energy performance evaluation of buildings based on occupant behavior.Energy and Buildings, 183, 659, 2019.

35. JIN Y.G., CHANG R. Environmental regulation and industrial total factor productivity -an empirical study based on dynamic panel data of 280 prefecture-based cities. Economic issues, 11, 18, 2016. 